\title{
Por que escritura rimada es mejor decorada: nueva revisión sobre la lengua, métrica y estilística de los Proverbios morales de Sem Tob
}

Por que escritura rimada es mejor decorada: new revision to the Language, Metrics and Stylistics of Sem Tob's Proverbios morales

Francisco PEDRo Pla COLOMER

Departamento de Filología Española

Universidad de Jaén

Campus Las Lagunillas $\mathrm{s} / \mathrm{n}$

Edificio de Humanidades y Ciencias de la Educación. Jaén, 23071

fpla@ujaen.es

Orcid ID 0000-0001-7121-8910

Resumen: Tomando como base metodológica el análisis de la métrica de los textos poéticos como fuente de reconstrucción lingüística, el presente trabajo tiene la finalidad de describir el componente fónico subyacente en los versos de los Proverbios morales de Sem Tob, en el marco de la estilística configuradora de los textos que formaron parte del segundo ciclo de la escuela del mester de clerezía. Para ello, se parte de una descripción histórico-literaria, cuya finalidad es la de complementar el análisis lingüístico, así como insertar el presente texto poético en su contexto filológico más adecuado.

Palabras clave: Historia de la lengua. Literatura medieval. Métrica. Fonética y fonología. Mester de clerecía.
Abstract: Taking as a methodological basis the meter analysis as a source of the language reconstruction, the current research has the aim of describing the phonic component which underlies in the verses of Sem Tob's Proverbios morales, in the framework of the text's stylistic of the second cycle of the mester de clerezía's school. In order to achieve this objective, this study will take into consideration historical-literary data as a complement of the linguistic analysis. It is expected, as the main objective, to reach the proper dating to insert the current text in its philological context.

Keywords: Historical Linguistics. Medieval Literature. Metrics. Phonetics and Phonology. Mester de clerecía. 
A partir del análisis de las rimas y el cómputo silábico de los versos, en estudios anteriores (Pla 2012 y 2014a) se ha desarrollado la tarea de reconstruir el componente fónico subyacente de la lengua castellana medieval desde una perspectiva filológica integral, es decir, tomando en consideración la materialidad textual conservada de los textos poéticos en su contexto histórico-cultural correspondiente desde los primeros testimonios hasta aquellos compuestos en el reinado de los Reyes Católicos.

Esta metodología hunde sus raíces en la tradición filológica iniciada en la península por el magisterio de Ramón Menéndez-Pidal. No resulta casual, por tanto, que fonólogos y lingüísticas como Tomás Navarro Tomás o Fernando Lázaro Carreter dedicaran atención merecida al estudio de la métrica española debido a la estrecha relación existente entre pronunciación y verso. Por la misma razón, Juan Corominas, Rafael Lapesa (1981; López de Ayala) o Emilio Alarcos (1951; 1987), entre otros, han atendido siempre a razones métrico-fonológicas a la hora de interpretar adecuadamente el valor de los textos poéticos. Es el caso también de estudios más recientes de Manuel Ariza (2012) o María Teresa Echenique (2013), quien ha subrayado la necesidad de estudiar sistemáticamente el componente fónico a través de, entre otros medios posibles, la métrica de los versos.

En el presente trabajo nos proponemos ahondar en estas hipótesis a partir del análisis de los versos que conforman los Proverbios morales de Sem Tob. Para ello, es necesario concretar los rasgos compositivos de la escuela del mester de clerezía (término al que atendieron estudiosos como Gerold Hilty e Isabel Uría 2000) que, seguramente, sobrepasó los límites cronológicos del siglo XIII y alcanzó, a modo de aprendizaje teórico-práctico inserto en el programa educativo del trivium, a los poetas del siglo XIV. La clerezía, por tanto, fue un saber adquirido mediante el aprendizaje de las artes liberales, especialmente la gramática, la retórica y la dialéctica. Además de conocer la lengua latina y las reglas de metrificar, el mérito de estos poetas fue el de rimar y leer las estrofas monorrimas en el marco cultural abrupto e innovador de su tiempo (Perry; Manzano), que abarca desde la corte de Alfonso XI (1312-1350) y Pedro I (1350-1369) hasta el asentamiento de la dinastía de los Trastámara.

Los estudios filológicos de carácter integral, además de precisar del conocimiento de datos histórico-literarios, requieren análisis detallado de la materialidad textual conservada para su correcta interpretación. Desde esta perspectiva, se ha llevado a cabo el estudio pormenorizado de los textos poéticos del siglo XIV: la Vida de San Ildefonso (Pla 2015a), el Libro de miseria de omne 
(Pla 2015d), el Libro de Buen Amor (Pla 2015b y 2015c) y el Rimado de Palacio (Pla 2014b). Abordar el estudio de la obra de Sem Tob supone describir los rasgos lingüísticos (estructura silábica, apócope, proceso de aspiración de F- latina, desfonologización del par fonemático bilabial, etc.), al tiempo que, desde la perspectiva estilística textual, poner al día el estudio de los rasgos métricos empleados por el poeta judío. Para ello se tendrán en cuenta tanto las investigaciones ya clásicas de Emilio Alarcos $(1951 ; 1987)$ o Ignacio González (1940; 1950), como las más recientes de Carlos Mota o Domínguez Caparrós (2006; 2014), entre otros (Zemke).

El acercamiento al componente fónico documentado en el texto poético de Sem Tob permitirá esclarecer los distintos niveles sociolectales de la lengua castellana medieval, tanto en lo referente a la esfera de mayor prestigio, como a la popular (es el caso del episodio de las Serranas y de don Pitas Payas en la obra del Arcipreste de Hita). Esto supone el análisis sistemático del vocalismo y consonantismo, atendiendo al alto grado de variación que pervivía en esta época, ya se trate de rasgos correspondientes a la oralidad, como aquellos heredados de la tradición discursiva poética (conservación de estructuras silábicas artificiales, mantenimiento de la apócope como herramienta para regularizar la métrica de los versos, etc.). De esta manera, la investigación emprendida en estas páginas pretende complementar, en la medida de lo posible, la cronología relativa del componente fónico de la lengua castellana en el contexto poético del segundo ciclo de la escuela del mester de clerezía.

\section{HACIA UNA ESTILÍSTICA HISTÓRICA: LOS PROVERBIOS MORALES Y EL MES- TER DE CLEREZÍA}

Es en el marco cultural de la corte de Alfonso XI (1312-1350) y Pedro I (13501369) donde adquieren sentido los rasgos estilísticos que impregnan con renovada originalidad los versos de Sem Tob (Shepard), como así hicieron con anterioridad el autor del Libro de miseria de omne, que adaptó el octosílabo a los versos alejandrinos de la cuaderna vía, y el Arcipreste de Hita, que concilió la mezcla indistinta de diversos tipos de versos (alejandrinos de dieciséis sílabas e introducción de formas estróficas como el zéjel y la octava de arte mayor). La composición de los Proverbios morales forma parte de esta corriente vanguardista que permite a Sem Tob combinar la tradición poética de mayor prestigio en el reino de Castilla con la métrica semítica y latina, basada en 
dísticos de arte mayor con presencia de rima interna y homoioteleuton. El resultado es un poema innovador, dedicado a Alfonso $\mathrm{XI}^{1}$ y dirigido, tras su muerte, a su hijo Pedro I (1350-1366), que contrariamente a la idea expuesta por Castro (532), "no constituye una obra aislada en el conjunto de las letras hispánicas” (Díaz-Mas/Mota 91).

\subsection{Transmisión y recepción de los Proverbios morales}

Los versos de los Proverbios morales han sido transmitidos a través de manuscritos procedentes del ámbito de la escritura y la oralidad (Ancos), en torno a un siglo posterior a su proceso de composición. Somos conscientes de la dificultad que conlleva el hecho de que ninguno de los testimonios conservados ofrezca el texto en su integridad, además de la complicada tarea de diferenciar rasgos originales del autor de aquellos introducidos por los copistas, factor que ha suscitado perspectivas divergentes en el proceso de reconstrucción textual. Por tanto, es necesario describir, aunque sea de manera concisa, la diversidad de testimonios conservados (Taylor) para conocer la naturaleza del ámbito de transmisión y composición de la obra:

-Ms. C (c. primeros decenios del siglo XV). Escrito en aljamía hebraica, representa la fuente principal más fidedigna para reconstruir el supuesto texto originario, como así lo manifiestan las múltiples ediciones desde la de González Llubera. Presenta los versos en renglón seguido, es decir, cada estrofa es un párrafo. Este manuscrito pone de manifiesto la relevancia de este autor para el pueblo judío, ya que un copista habría transcrito el original con grafías latinas empleando caracteres hebraicos para una mayor difusión. ${ }^{2}$

-Ms. $M$ (siglo XV). Presenta los versos de Sem Tob en dos columnas, en estrofas de cuatro versos de arte menor, seguramente por la influencia ejercida

1. Muestra de ello es la estrofa 712, en que los manuscritos $N$ y $E$ documentan $<$ don Alfonso $>$, posible variante originaria, mientras que $C$ ofrece la lectio <don Pedro>, modificación tardía tras la muerte de Alfonso XI: Del lobo e del zebro: ¿Por qué alongaremos? / Al noble rrey don Pedro estas mañas veemos. (ms. C) / Del lobo e del osso: ¿Por qué alongaremos? / Al buen rrey don Alfonso estas mañas veemos. (mss. $N$ y $E$ ).

2. En cambio, investigadores como Mota mantienen la idea de que el original habría sido escrito en texto aljamiado, en base a la materialidad textual del ms. C: "La vida literaria de estas comunidades se desarrolló prioritariamente en su propia escritura, con independencia de la lengua que empleasen, hebrea o romance [...] fuera o no don Pedro capaz de descifrar la aljamía, casi cualquiera de sus cortesanos judíos pudo leerla para el monarca" (1373). Comparto con Deyermond la idea de que "se trata más bien de una muestra del pensamiento judío en una forma poética hispánica" (212), seguramente escrita en caracteres latinos. En cualquier caso, no es posible descartar la idea de que el rey hiciera leer en voz alta muchas de las obras destinadas a su persona. 
por la tradición cancioneril. Es el único testimonio que conserva un prólogo de un comentador anónimo.

- Ms. $N$ (siglo XV). Sigue muy de cerca a $M$. Antes del texto aparece un explicit en alabanza a la Virgen María, signo evidente de una copia con fines didáctico-religiosos.

-Ms. E (siglo XV). El texto aparece copiado en estrofas de cuatro versos, totalmente refundidos, a una columna, junto a textos como la Danza general de la muerte o el propio Poema de Fernán González (hecho que demuestra que el texto del rabino se interpretaba, por parte de sus receptores no inmediatos, como poema inserto en la tradición del mester). Presenta el texto modernizado, cuya materialidad textual corresponde a un estadio lingüístico más avanzado que la época de nuestro autor.

-Ms. CU (finales del siglo XV). Testimonio derivado de la oralidad. Es parte de un expediente inquisitorial durante un procesamiento por herejía y apostasía contra el converso Ferrán Verde por sus lecturas de raigambre semítica. Como respuesta ante el tribunal, logró copiar de memoria 219 estrofas de los Proverbios morales, en versos cortos, en orden totalmente distinto al que presentan los otros manuscritos.

1.2 Estudio métrico de los Proverbios morales en el marco poético de la escuela del mester de clerezía

En el contexto cultural de la corte de Alfonso Onceno, los poetas fueron los principales testigos y promotores de los nuevos rumbos intelectuales. Los gustos literarios, así como la revolución lingüística acaecida en esta época, permitieron la acomodación de innovadoras estructuras silábicas en moldes métricos inexistentes en la centuria precedente; el empleo de herramientas métricas como la sinalefa o compensación silábica de los versos trajo consigo el abandono de los rígidos corsés métricos empleados en los poemas del mester de clerezía del siglo XIII.

Investigadores como Ignacio Llubera o Paloma Díaz-Mas y Carlos Mota incluyen el poema de Sem Tob en la clerecía rabinica cuatrocentista de raigambre hispanojudía, compuesta por poemas que comparten, además de una cultura y cosmovisión específica, rasgos formales como el empleo del verso alejandrino o la rima zejelesca (que también se encuentra en el Libro de Buen Amor). En este grupo se incluyen las Coplas de Yoçef, El pecado original, las Lamentaciones del alma ante la muerte y los Proverbios morales. En cambio, esta 
última es algo más que una recopilación de sentencias, ya que, además de formar parte de la escuela del mester de clerezía, "participa de un mestizaje (inter) cultural. Al tiempo de dirigirse a los cristianos en la persona de su máximo dignatario, el Rey, apuntan a la vez más lejos y más hondo: a la dignificación de la condición judía, que el poeta posee mancomunadamente con sus verdaderos destinatarios" (Ivanovici 5).

La recepción primaria, en este caso el rey de Castilla, confiere sentido a la propia forma métrica empleada: el alejandrino heptasílabo. Las características socio-culturales de la época permitieron a Sem Tob cruzar en ese mestizaje poético el ritmo y las rimas semíticas con la tradición poética del sociolecto de mayor prestigio (Kleinschmidt) para conformar un poema narrativo didáctico-moral que, en palabras de Baer, conoció desde su aparición un doble circuito de difusión cristiano-judío.

\subsubsection{Métrica y rima}

Desde los estudios llevados a cabo por Alarcos $(1951 ; 1987)$, quedan resueltas ciertas irregularidades adoptadas por otros editores, quienes habían seguido el principio de rima consonante absoluta desde la última sílaba acentuada. Alarcos (1951) argumenta que las formas documentadas en el manuscrito $C$ no deben restituirse en el proceso de reconstrucción de este texto, ya que pertenecen al tipo bomoioteleuton o rima de los últimos elementos silábicos átonos.

La existencia de rimas internas, en posición de cesura métrica, ha dado lugar a interpretaciones heterogéneas sobre la disposición versal. Tanto en las ediciones de Álvarez, García y Shepard como en la investigación de Marcelino García se continúa la idea de que el texto original habría sido compuesto por versos heptasílabos distribuidos en estrofas de cuatro versos con rima consonante y alterna, estrofa conocida como la redondilla cruzada propia de

3. Si bien es cierto que existen diferencias que separan los textos escritos en cuaderna vía de los siglos XIII y XIV, las semejanzas que los aproximan son, por otro lado, innegables: el uso de los mismos pies métricos, el empleo de rimas consonantes en estrofas monorrimas, así como la estrecha relación entre significante y significado poético. Por estas razones, los poemas insertos en la tradición del mester a lo largo del trescientos constituyen un conjunto de textos configuradores de un segundo ciclo de esta escuela, más innovador y abrupto. La regularidad a sílavas contadas persiste en todos estos poemas narrativos como ideal poético que, desde principios de la centuria precedente, se prolongará a lo largo de los siglos XIV y XV. Así entendido, los versos castellanos medievales se midieron tanto por imperativos poéticos como por las características lingüísticas de cada época desde una perspectiva plenamente isosilábica, rasgo que también impregna los versos alejandrinos heptasílabos de los Proverbios morales. 
las coplas sefardíes de los siglos XVIII y XIX (Domínguez Caparrós 2006, 51). Sin embargo, si nuestro autor escribió un poema narrativo según los criterios métricos de la escuela del mester, no es posible mantener esta hipótesis. Además, si lo combinamos con la idea de que los textos líricos de arte menor se vinculan con la consolidación más tardía de la tradición cancioneril, es más apropiado creer que Sem Tob compuso versos alejandrinos heptasílabos isosilábicos $(7+7)$ con rimas internas, idea compartida por las ediciones de González Llubera y Díaz-Mas/Mota y especialistas como Alarcos (1951), Deyermond, Domínguez Caparrós (2006; 2014), Mota, Ivanovici o Girón Negrón, entre otros muchos.

Nuestro poeta, influido por la tradición poética semítica y latina, devuelve al alejandrino su condición más primitiva con hemistiquios isosilábicos heptasílabos distribuidos en dísticos, forma predilecta del verso moralizante, con una fuerte cesura acentuada por la introducción de una rima secundaria (Uría 1990). En final de verso, los elementos fónicos coincidentes sobrepasan, en la mayoría de los casos, la última sílaba y, por tanto, podrían ser interpretadas como rimas consonantes. Todo ello origina un texto situado en un cruce de caminos culturales coincidente con un entorno literario innovador.

Mota, por su parte, defiende la impronta semítica en base al empleo métrico-rítmico del llamado verso largo o Ha-Arok: óoo / óooo // óoo / óooo (1380). En este caso, el paso del empleo de estos pies métricos a los del alejandrino castellano no habría supuesto dificultad alguna para Sem Tob, ya que las cláusulas que conforman los hemistiquios del mester se combinan en variantes silábicas semejantes $2+5,5+2,3+4$ y $4+3$. La anacrusis se metrifica y las cláusulas rítmicas se configuran sobre unidades léxicas, respetando las pausas naturales entre ellas, por lo que existe la cesura y la dialefa de manera generalizada (Uría 2000). Todos estos rasgos, por lo tanto, mantienen cercanía estilística suficiente como para que el rabí desarrollara sin problemas su poema narrativo en la versificación propia de la tradición poética castellana de la centuria precedente: "los heptasílabos de los Proverbios morales corresponden al tipo más ortodoxo de la cuaderna vía" (Deyermond 213).

La variabilidad de las decisiones tomadas en el proceso de reconstrucción métrica resultó en la heterogeneidad presentada por los manuscritos conservados. Sin embargo, los pareados alejandrinos con rima interna se corresponden con el marco evolutivo de la escuela del mester del siglo XIV, bañada por la tradición de raigambre semítica en el proceso de creación de este poema. 


\section{DESCRIPCIÓN FONÉTICO-FONOLÓGICA}

La preocupación por parte de los editores acerca de la lengua de los Proverbios morales se ha basado en la materialidad de los manuscritos conservados: "No reflejan el habla de las aljamas castellanas, y las variantes son el resultado de la transmisión escrita, y probablemente oral, de los sucesivos copistas que añadían o eliminaban, como es usual en los manuscritos medievales" (Shepard 74). Muchos de los rasgos descritos han estado vinculados con el conservadurismo lingüístico del autor (casos de apócope, conservación de estructuras heterosilábicas, etc.), otros, sin embargo, se han relacionado con el influjo semítico, sobre todo en base al empleo de la rima de tipo árabe, la frecuencia del hipérbaton o el paralelismo en el período oracional, entre otros.

A continuación tiene desarrollo el estudio del vocalismo y el consonantismo documentado en los versos de los Proverbios morales para arrojar luz sobre el supuesto artificio y conservadurismo lingüístico de Sem Tob, quien fue perfectamente conocedor de la lengua castellana y su tradición poética. A fin de homogenizar los ejemplos seleccionados, se ha optado por emplear la edición de Díaz-Mas y Mota como texto base para la citación del corpus, teniendo en cuenta la compleja y múltiple variatio de los manuscritos conservados. Todo ello se verá complementado por la perspectiva que ofrece el análisis de la métrica y la rima, así como con los resultados obtenidos por los estudios más recientes de Lingüística histórica.

\subsection{Vocalismo}

\subsubsection{Diptongos, hiatos y monoptongación}

a) La tendencia a diptongar las vocales breves latinas en sílaba tónica pervive en estructuras donde el castellano ha mantenido la solución monoptongada ${ }^{4}$. El diptongo creciente de <ruestro $>$ del verso 82 b podría haber estado motivado por la rima consonante con <encuentro>, siempre con la precaución de que la rima de tipo homoioteleuton no es para nada sistemática en la conformación de las estrofas, sino que formó parte del sistema estrófico caracteri-

4. La pervivencia de variantes diptongadas como <enpuesty> ('en pos de ti') del verso 509a, documentada únicamente en el ms. $C$ y mantenida por editores como Shepard y Díaz-Mas/Mota, se encuentra en estrecha relación con otras estructuras tautosilábicas empleadas en los versos del Arcipreste de Hita (con ceniza los cruza de ramos en la fruente, 1178b) y de López de Ayala (del vientre a la fuesa fuera toda mi vía, 1034d). 
zado por Sem Tob en que toda rima consonante es homoioteleuton, pero no viceversa:

Con frío fazel fiesta e le sale al encuentro, al que da en la tiesta es la puerta en ruestro. < RŎSTRU (82)

b) Se mantienen como diptongos las estructuras que en el primer ciclo del mester se articulaban como hiatos: [3us.tí.tsi.a] > [3us.tí.tsja], [ma.lí.tsi.a] > [ma. lí.tsja] y [kri.a.ðór] > [krja.ðór]. Esta tendencia, similar a la preferencia actual por la diptongación (Barberia 80; Recasens), forma parte del proceso de asentamiento de las estructuras silábicas del que participó la lengua castellana durante la primera mitad del siglo XIV. El análisis métrico del Libro de Buen Amor, el Libro de miseria de omne y el Rimado de Palacio han conducido a resultados semejantes, por lo que es preferible mantener la secuencia tautosilábica en $<$ Criador $>$ [krja.ðór] y no apocopar <commo $>$ en el caso del verso $25 \mathrm{a}$, como así atestigua la lectio de $M$ y $E$ :

\begin{tabular}{ll} 
VERSO & ESCANSIÓN \\
\hline ¿Commo seria tan granda commo la del Criador, < CREATŌRE (25a) & Òooó oóo / óoo òoó(o) \\
\hline $\begin{array}{l}\text { Que, cuando es del punto a la rueda justiçia < IUSTITIA } \\
\text { non monta del más justo ante la su maliçia. < MALITIA (14) }\end{array}$ & oóo òoóo / òoóo oóo oóo / óoo òoóo \\
\hline
\end{tabular}

c) Muchos hiatos secundarios pasaron a articularse como diptongos ([réi]). La pervivencia de ciertas formas con hiato tras pérdida consonántica ([me.a.tát] / [mi.a.tát], [3u.és] y [3u.í.czjo]) habrían servido como medida para la regularización métrica. Estas variantes residuales mantuvieron su vigencia durante toda la centuria, viéndose reforzadas seguramente por la caracterización del ámbito de recepción al que iban dirigidas estas obras (Pla 2014b). En el caso de Sem Tob, pocos son los ejemplos documentados con estructura hiática $\mathrm{V}_{1} \cdot \mathrm{V}_{2}$, rasgo que parece alejar su lengua del supuesto arcaísmo que otros investigadores han querido ver en la obra: 
PLA COLOMER. LENGUA, MÉTRICA Y ESTILÍSTICA DE LOS PROVERBIOS MORALES DE SEM TOB

\begin{tabular}{ll} 
VERSO & ESCANSIÓN \\
\hline Por que la miatad de cuanto oyermos fablemos, < MEDIETATE (568a) & oóo òoóo / òoóo oóo \\
\hline al noble rey don Pedro estas mañas veemos. < RĕGE (712b) & oóo òoóo / òoóo oóo \\
\hline Es meatad muy fea poder con desmesura: < MEDIETATE (716a) & òooó oóo / oóo òoóo \\
\hline juïzio e verdat e paz que d'ellos vien. < IUDICIU (359b) & oóo òoó(o) / oòoóo ó(o) \\
\hline Pero el jüez malo, él fázese muy franco: < IUDICE (358a) & óoo oóoo / oóoo oóo \\
\hline Eel juïzio es la piedra çimental; < IUDICIU (360a) & oòoóo ó(o) / oóo òoó(o) \\
\hline
\end{tabular}

d) Según la métrica y las rimas de Sem Tob, la forma $<$ judio $>$ (< IUDAEU) se documenta como hiato [зu.ðí.o] y como diptongo [zu.ðjó], hasta su posterior asentamiento a partir de la segunda mitad del siglo XIV, reflejo de una época de cambios sustanciales en la lengua:

\begin{tabular}{ll} 
VERSO & ESCANSIÓN \\
\hline que viene dezir Santo, judío de Carrión, (1b) & oòooó óo / oóo òoó(o) \\
\hline $\begin{array}{l}\text { Non val el açor menos por nasçer de mal nido, } \\
\text { nin los enxemplos buenos por los dezirjudío. (64) }\end{array}$ & oòooó óo / ooó òoóo \\
\hline No'm desdeñen por corto, que mucho judió largo (65a) & ooooó oóo \\
\hline E la merçed qu'el noble, su padre, prometió, & òoóo oóo / oòooó óo \\
\hline la terná, como cumple, al Santob el judió. (725) & oòoó oóo / oóo òoó(o) \\
\hline
\end{tabular}

e) Muchas estructuras heterosilábicas, procedentes de la pérdida de una consonante intervocálica, monoptongaron en una sílaba, es el caso de ser ([se. dé.re $]>[$ se.ér $]>[$ sér $])$, ver $([\beta i . d e ́ . r e]>[\beta$ eér $]>[\beta e ́ r])$ o $\operatorname{creer}([$ kré.de.re $]>[$ kre. ér] $>$ [krér]). En contraste con las formas monoptongadas en el Libro de miseria de omne, en los versos de Sem Tob predomina la variante con hiato, rasgo culto y latinizante del poeta, lejos de una intención arcaizante:

\begin{tabular}{ll} 
VERSO & ESCANSIÓN \\
\hline Qu'el derecho del arco es seer tuerto fecho, $(93 a)<$ SEDEERE & òoóo oóo / òoó òoóo \\
\hline E mucho omne entendido, por seer vergonçoso, (68a) < SEDËRE & òoóo oóo / òoó òoóo \\
\hline al mundo non venieste por ser abantajado. $(320 b)<$ SEDEERE & oóo òoóo / oó oòoóo \\
\hline Los sabios que quería veer, los fallara (330a) < VIDĒRE & oóo òoóo / oó oòoó(o) \\
\hline al noble rey don Pedro estas mañas veemos. $(712 b)<$ VIDËMUS & oóo òoóo / òoóo oóo \\
\hline Efaze d'él escarnio Dios, por que quier creer (186a) < CREDËRE & oóo òoóo / òoo òoó(o) \\
\hline
\end{tabular}


El manuscrito $C$ muestra preferencia por la representación de estas formas con hiato. Muchas de ellas no se corresponden con la oralidad del poeta, ya que, dada la métrica de los versos donde se insertan, las voces <sofreença> (272b) y <rreprehende> (622a) se articularían con estructuras monoptongadas: [so. frén.tsa] y [re.prén.de], como así se observa en la materialidad gráfica de $M N E$, por lo que no sería necesario asumir la apócope del pronombre personal $<$ se $>$. Díaz-Mas y Mota prefieren la opción por la diptongación <sofriença>, pero parece preferible optar por la variante monoptongada con vocal palatal media en consonancia con los derivados de la variante común medieval <sofrir > (Corominas/Pascual s. v. SUFRIR, 333):

\begin{tabular}{ll} 
VERSO & ESCANSIÓN \\
\hline nin tal varraganía com la buena sofreença $(272 b)<* S U F F E R R E N T i A$ & oó oòoóo / òoóo oóo \\
\hline De todo quanto faze el omne se rreprehende; $(622 \mathrm{a})<$ REPREHENDET & oóo òoóo / oóo òoóo \\
\hline
\end{tabular}

\subsubsection{Monoptongación del sufijo /-iello/}

El reinado de Alfonso Onceno representa la etapa cronológica de apertura de la monoptongación del morfema sufijo /-iello/, procedente del latín -ĚLLU y sus derivados (Lapesa 1981, 248). Tanto en el Libro de miseria de omne como en el Libro de Buen Amor destaca la paulatina generalización de la variante monoptongada. En los Proverbios morales todavía hay rimas que documentan pervivencia de la articulación tautosilábica que, de forma residual, habría llegado hasta los poetas del Cancionero de Baena, es el caso de la rima homoioteleuton entre <poquiella $>$ ([po.kjé.Ka]) y <ella> ([é.Ka]):

Porque pisan poquiella sazón tierra, perlando, < PAUCU ĔLLA omes que pisa ella para siempre callando, (54) < ILLLA

Las rimas internas y finales, compuestas por voces cuyo étimo latino no contenía una vocal breve tónica, justifican la generalización articulatoria de la variante monoptongada, como <villa $>$ ([ßí.Ka]) con <maravilla $>$ ([ma.ra.ßí.Ka]) y <anillo $>$ ([a.ní.Ko]) con <capillo $>$ ([ka.pí.Ko]):

Por que toda la villa que faze algo de nada < VILLA

vean la maravilla de Dios cuánto es granda. (12) < MIRABILǏA 
Quien dedos tiene, fuerça non faga del anillo; < ANĚLLU guarde Dios la cabeça: non menguará capillo. (380) < CAPĬLLU

Vezino de Castilla por él su entençión sabe el de Sevilla ${ }^{5}$ e la su condiçión. (705)

En base al criterio obtenido por el análisis fónico-métrico, no parece coherente sustituir de manera sistemática las variantes monoptongadas documentadas en los manuscritos, como así lo quiere Alarcos: "Lo más probable, sin embargo, es que, dado el carácter arcaizante en general del poema, Sem Tob usara la forma sin reducir -iello" $(1951,268)$. La rima homoioteleuton no pareció influir en la pronunciación de estas variantes; además, desde una perspectiva más amplia, la mayoría de las rimas tienden a la perfecta consonancia a partir del último acento prosódico. Sem Tob habría sido consciente de emplear este recurso poético entre cuyos parámetros poéticos tuvo cabida, a su vez, la rima prosódica de tradición semítica.

\subsubsection{Variantes morfológicas del pretérito imperfecto y condicional}

Desde estudios como los de Malkiel (1959) hasta los más recientes (Company), se subraya la importancia del cambio de siglo en lo referente a la modificación fonética de las variantes morfológicas del pretérito imperfecto y condicional. En posición de rima, Sem Tob emplea siempre la forma con hiato, ya generalizada en la oralidad desde finales del reinado de Alfonso Onceno y los sucesivos gobiernos de los Trastámara. La rima de los sustantivos <dia $>$ ([dí.a]) o <via $>$ ([ßí.a]) y del adjetivo < vazia $>$ ([ßa.dzí.a]) asegura la articulación de las variantes verbales con estructura heterosilábica:

Yo del papel saqué la razón que dezía; < DICĒBAT

con ella me finqué, dile carta vazía. (44) < VACĪVA

5. Todavía en 1313 se documenta en el Fuero Briviesca (BN ms. 9199) la forma diptongada <Seuiella>: Et por ende nos don alfonso por la gracia de dios. Rey de Castiella de Toledo. de leon de Gallizia de Seuiella de Cordoua de Murçia de Iahen de badaioz. de Baesça \& del algarbe entendiendo en commo las villas de nuestro Regno de Castiella que non ouieran fuero fasta en el nuestro tiempo \& judgauanse por fazañas \& por aluedrios departidos de los omnes (CORDE). Seguramente la influencia lingüística de la tradición jurídica de los fueros, más conservadora y tradicional, motivó el empleo generalizado de esta variante en contienda con el resultado monoptongado, solución generalizada para este topónimo en los siglos XIII y XIV. 
Sonará; verná día avrá su libra tal < DIES

presçio como solía valer el su quintal. (51) < SOLĒBAT

El que desearía, cuan no'l tobiese a ojo, < DESIDĒRE HABĒBAT

veyendol toda vía, toma con él enojo. (206) < VĪA

Únicamente se documentan dos casos en que Sem Tob emplea la variante diptongada en posición de rima para la primera persona del plural del condicional: ${ }^{6}$

El día de yer tanto alcançar non podriemos < POTĒRE HABEBAMUS

nin mas nin menos cuanto oy mil años fariemos. (122) < FACĔRE HABEBAMUS

Sin fuego e sin reja del pan nunca conbriemos; < COMEDĔRE HABEBAMUS lo nuestro, sin çerraja e llave non guardariemos. (648) < der. germ. *warda

El análisis métrico de los versos revela persistencia de variantes tautosilábicas, como documentan el Libro de Buen Amor y el Libro de miseria de omne, rasgo lingüístico que todavía formaba parte del sociolecto de mayor prestigio. Más tardíamente, en el Rimado de Palacio, López de Ayala emplea la forma diptongada, ya arcaica y en desuso, como herramienta para la regularización de sus versos, del mismo modo que los poetas correspondientes al reinado de los Austria (Lapesa 2000c, 766):

6. Documentación que refuerza la idea de que en el paradigma verbal de pretérito imperfecto la primera persona del singular fue la primera en regularizar su estructura silábica, en contraste con el resto de formas personales, con la finalidad de evitar la homomorfia con la tercera persona del singular: "La reacción contra las formas -ié, -ié se produce en el s. XIV. [...] en Juan Ruiz domina también -ía, pero con gran fuerza aún de -ie. Esta forma fue quedando como popularismo o regionalismo (el habla de Castilla la Vieja la eliminó antes que Toledo o León). En el s. XV es casi general -ía, pero aún los ejemplos de -íe no son una rareza" (Lapesa 2000c, 765). Estas palabras complementan la teoría expuesta por Malkiel $(1959,474)$ : "In the process one of the steadily advancing forms, vendiémos, moves precariously close to imperf. vendíamos, which $[\ldots]$ most speakers [...] were bound to pronounce vendiámos, at least in allegro speech. $[\ldots]$ vendiémos and vendiámos may have occurred interchangeably in numerous contexts". 


\begin{tabular}{ll} 
VERSO & ESCANSIÓN \\
\hline ¿Como seria tan granda como la del Criador (25a) < SEDËRE HABEBAT & òooó oóo / óoò òoó(o) \\
\hline Teníame por muerto, mas vínom al talante $(18 \mathrm{a})<$ TENËBAT & oóoo oóo / oóoo oóo \\
\hline Seria cosa estraña, muy fuera de natura, $(28 \mathrm{a})<$ SEDËRE HABEBAT & oóo òoóo / oóo òoóo \\
\hline $\begin{array}{l}\text { Sería muy buen omre quien sopiese obrar < SEDËRE HABEBAT } \\
\text { tanta buena costumre que yo sabria nomrar. (440) < SAPËRE HABEBAT }\end{array}$ & oóoóoóo oóo / òoóo oó(o) \\
\hline
\end{tabular}

Los manuscritos atestiguan tanto la grafía $<$ ie $>$ como $<$ ia $>$ para representar la secuencia tautosilábica que podría haber encubierto una etapa intermedia fónica del tipo [iə], es decir, "un elemento acentuado, que se escinde en cuanto a su abertura" (Alarcos 1990, 222). La contienda de variantes en los versos de Sem Tob forma parte del proceso de nivelación lingüística durante al reinado de Alfonso Onceno, en que se consolidó la estructura silábica, monoptongada en el caso del sufijo /-iello/ > /-illo/ y heterosilábica en lo concerniente al paradigma verbal de pretérito imperfecto y condicional, articulación subyacente que también debe ser aplicada a la materialidad textual correspondiente al prólogo en prosa (en tanto se tratan de formas verbales de tercera persona del singular), conservado tan solo en $M$ y compuesto con posterioridad durante el proceso de transmisión textual (tomado de la edición de Shepard):

pero non se le entendia nin seria sabido que le bynya de Dios nin por acarreamiento del Espiritu Santo. Asy que non seria Dios tan conosçido. (61-63)

\subsubsection{Apócope, ¿recurso lingiuístico o estilístico?}

La apócope extrema era ya rasgo lingüístico obsoleto (Lapesa 1985a; 1985b), al tiempo que persistían formas con apócope autóctona (pérdida de vocal después de $[\mathrm{r}, \mathrm{s}, \mathrm{l}, \mathrm{n}, \mathrm{d}, \mathrm{s}])$, todavía documentadas en los poetas del Cancionero de Baena:

\begin{tabular}{ll} 
VERSO & ESCANSIÓN \\
\hline Efaze d'él escarnio Dios, por que quier creer (186a) < FACET & oóo òoóo / óoo òoó(o) \\
\hline Si se faz por ventura lo que a él plazía, (185a) < FACET & òoó òoóo / oòoó oóo \\
\hline e el que tien non deña, sinon otro estraño. (217b) < TĚNET & oòoó oóo / òoóo òóo \\
\hline Non pued omre aver en mundo tal amigo (344a) < PÖTEST & òoóo oó(o) / oóo òoóo \\
\hline el que non tiene nada non reçela perder. (416b) < TËNET & òoó òoóo / òoóo oó(o) \\
\hline De una fabla, conquista puede naçer, d'ý muerte, (457a) < PǑTEST & òoóo oóo / òooó oóo \\
\hline
\end{tabular}


La abundancia de casos con apócope autóctona lleva a pensar en la pervivencia de este rasgo como característica propia de la lengua castellana (Catalán; Folgar 2014), en convivencia con las formas plenas que fueron generalizándose gradualmente en el paradigma fónico desde la segunda mitad del siglo XIV. Estas variantes aparecen asimismo documentadas en el prólogo en prosa:

E por esto en el secreto de Dios vien lo que a nos non se entyende. (64-65) $<$ VĔNIT

En cambio, pocos son los ejemplos de apócope extrema que documenta el análisis métrico de los versos de Sem Tob, hecho coincidente con la teoría de Lapesa, para quien "la reacción contra la apócope extrema o la acomodación de los finales de palabra detonantes suponían una afirmación de las tendencias más profundas y duraderas de la fonología castellana” (1985b, 211). La lengua castellana, por tanto, "nunca alcanzó la intensidad apocopadora de otros idiomas románicos, como el catalán, el provenzal y el francés" (Folgar 2014, 31). Según la naturaleza métrica de los versos de los Proverbios morales, los pocos casos de apócope extrema afectan a palabras gramaticales y formas verbales:

\begin{tabular}{ll} 
VERSO & ESCANSIÓN \\
\hline non avria que valiese tanto com la franqueza; $(137 b)<$ QUOMŏDO & òoó òoóo / òoó òoóo \\
\hline Que sab que non naçieste por bevir apartado; (320a) < SAPYTT & oóo òoóo / òoó òoóo \\
\hline
\end{tabular}

En el caso de los pronombres personales se mantuvo la variante apocopada en convivencia con las formas plenas, hecho que permitía a los poetas medievales regularizar la métrica de los versos. Los resultados de la reciente investigación de Matute sobre la apócope de los pronombres personales no divergen de aquellos obtenidos por Echenique (1981), reforzados en un estudio más reciente (Echenique, en prensa), en lo referente al empleo variable según el tipo de discurso, siguiendo la estela de trabajos como los de Folgar (2012; 2014), Freixas o López Bobo, entre otros muchos.

La pervivencia de las formas apocopadas de los pronombres personales de tercera persona (más abundante para le, también en función de implemento $l o$, y en ningún caso para la forma femenina $l a)^{7}$ queda justificada por la mé-

7. Según Lapesa, abundan los casos de apócope de pronombres hasta entrado el siglo XV: "Opiniones muy autorizadas consideran que $-l$ es siempre la variante apocopada de $l e$. Sin embargo 
trica de los hemistiquios heptasílabos donde se insertan. ${ }^{8}$ Es necesario, por tanto, modificar la lectio de los manuscritos, que ofrecen la forma pronominal plena, en aras de recuperar el isosilabismo pretendido por Sem Tob, incluso para algunos casos de pronombres de primera y segunda persona, criterio asumido en la edición de Díaz-Mas y Mota:

\begin{tabular}{ll} 
VERSO & Escansión \\
\hline El nesçio non sabía que'l fize por infinta, (41a) (lo) & oóo òoóo / oóo òoóo \\
\hline El que lança la lança semeja'l vagarosa (74a) (le) & òoóo oóo / oóo òoóo \\
\hline El que le desearía, cuan no'l tobiese a ojo, (206a) (lo) & oóo òoóo / oòoóo óo \\
\hline el cuitado'l baldona, tien lo por enemigo. (655b) (lo) & òoóo oóo / óoò òoóo \\
\hline Con frío fazel fiesta e le sale al encuentro, (82a) (le) & oóo òoóo / òoóo oóo \\
\hline Que, puesto que no't venga daño por el primero, (436a) & oóo òoóo / óo òooóo \\
\hline Entregom en nomrarlas como si las sopiese (443a) & oóo òoóo / óoò òoóo
\end{tabular}

Desde la Vida de San Ildefonso (c. 1302) (Walsh) hasta los Proverbios morales, parece compartirse una misma tendencia articulatoria en los mismos contextos morfofonológicos: mayor tendencia al empleo de formas apocopadas del pronombre de tercera persona de singular <'l>, juntamente con la progresiva recuperación de la vocal final de los pronombres de primera y segunda persona del singular. La apócope de los pronombres no estuvo motivada únicamente por exigencias métricas del verso alejandrino, como así afirma Lázaro Carreter en el caso de la poesía cuatrocentista, sino que formaba parte de las posibilidades de la lengua castellana en toda su variabilidad sociolectal (como así lo pone de manifiesto el análisis de los versos del Libro de Buen Amor). Esto significa que no parece posible afirmar con rotundidad que las formas apocopadas hayan sido empleadas únicamente por imperativos métricos. Tampoco

creo que no hay razón para descartar que en función de acusativo proceda de $l_{0}[\ldots]$. En la forma apocopada $-l$ confluyeron, pues, el $l(0)$ del acusativo masculino y el $l(e)$ de dativos" (2000a, 280-81). En cuanto a su posición posverbal: "Los casos de apócope muestran claramente que los PA, en tanto que fonológicamente dependientes, son formas enclíticas que dependen de la palabra precedente" (Nieuwenhuijsen 1358). El análisis de los datos en los textos poéticos no parece concordar con la propuesta de Nieuwenhuijsen, para quien las variables apocopadas se perdieron en el siglo XIV, sino que mantuvieron su dependencia morfofonética con el elemento léxico precedente hasta su decadencia en el reinado de los Reyes Católicos, como lo atestigua el análisis métrico de los versos de Enzina.

8. Recuérdese que el adverbio de negación y la conjunción disyuntiva podían pronunciarse desde la época de Alfonso XI como [nó] / [nón] y [ní] / [nín] (Pla 2014a). 
representa rasgo arcaizante, como afirma Alarcos: "Muchos de estos casos son, indudablemente, debidos a las necesidades métricas; pero, a pesar de ello, son un detalle más que va de acuerdo con el carácter arcaizante de los Proverbios" (1951, 273).

Las variantes con pérdida vocálica (apócope, síncopa, aféresis y elisión) formaban parte de las posibilidades lingüísticas que ofrecía la lengua castellana en la primera mitad del siglo XIV, aprovechadas por los poetas en beneficio del isosilabismo de sus versos. Gracias a la aplicación de las teorías evolutivas proporcionadas por la Lingüística histórica, es posible afirmar que no se trató de variantes artificiales producidas por exigencias métricas, como así quieren Díaz-Mas y Mota (53), entre otros muchos investigadores.

\subsection{Consonantismo}

\subsubsection{Labiales}

a) Las rimas de los Proverbios morales, internas y finales, manifiestan articulación diferenciada entre los fonemas $/ \mathrm{b} / \mathrm{y} / \beta /$.

Únicamente se constata una rima que, desde el punto de vista de la consonancia poética, parece apuntar a una articulación originada por la desfonologización de este par fonemático. La influencia de la rima homoioteleuton imposibilita conocer, a ciencia cierta, la articulación subyacente de <sabio> ([sá.bjo] o [sá.ßjo]) en rima con <agrabio> ([a.grá.ßjo]). Según Corominas y Pascual (s. v. SABER 114) se postula un étimo del latín vulgar *SABǏU que originó savi (cat. y oc.), sage (fr.) y savio (it.), aunque los resultados castellano y portugués se correspondiesen con la forma clásica SAPIDDU (Wartburg $s . v$. SAPIO):

Que faz bien a menudo al torpe; e al sabio, < SAPI็DU mal, e al entendido -de aquesto non me agrabio-; < *AGGRAVIU (97)

Las vacilaciones gráficas se documentan en $C$, ya que $M N E$ tienden a presentar generalmente $<\mathrm{v}\rangle \mathrm{y}<\mathrm{b}>$ según su valor fónico correspondiente, $[\beta]$ y [b] respectivamente (como <lubia>, ms. $C$, frente a <lluuia>, mss. MNE, del verso 207a). En este caso, y según los datos que aportan los estudios de Dámaso Alonso o Manuel Ariza (2012), entre otros, es preferible mantener la lectio que ofrecen $M N E$, ya que las desviaciones gráficas de $C$ podrían haber sido 
causadas por el usus scribendi del copista. Tampoco resultaría extraño que en el supuesto original se manifestaran rasgos de confusión, como en la rima de la estrofa 97, ya que el Libro de Buen Amor documenta la apertura del proceso de desfonologización de bilabiales.

b) La grafía $<\mathrm{f}->$ encubría una articulación fricativa sorda, seguramente bilabial (Ariza 2012, 135), ya que la aspiración era sentida como rasgo lingüístico vulgar hasta el siglo XV. El recurso de la dialefa métrica señala contenido fónico para la grafía $<\mathrm{f}->$ :

\begin{tabular}{ll} 
VERSO & ESCANSIÓN \\
\hline cuando faz frío como cuando faze calura. $(81$ b) < FACIT & òooóo óo / òoóo oóo \\
\hline Non cude que fue fecho jüez por que presente $(366 a)<$ FACTU & oóo òoóo / oóoo oóo \\
\hline Cuando el rey don Alfonso finó, fincó la gente $(3)<$ der. *FIGICARE & òoó òoóo / oó oòoóo \\
\hline
\end{tabular}

La única documentación que apunta a una incipiente articulación aspirada es la voz <hynche> del verso $212 \mathrm{~b}$. La grafía <h->, en este caso, aparece documentada únicamente en $C$, en tanto $M N E$ ofrecen <finche>, forma que debería ser respetada por los editores, aunque ninguno así lo considere, ya que representa la articulación correspondiente al sociolecto culto del poeta en el momento de la composición textual.

\subsubsection{Dentales}

a) Se constata articulación bisílaba con mantenimiento de la consonante intervocálica en las formas verbales de tratamiento de segunda persona del plural (Lapesa 2000c, 742):

\begin{tabular}{ll} 
VERSO & ESCANSIÓN \\
\hline $\begin{array}{l}\text { Uno a otro a grandas bozes diz: - ¿Do entrades? < INTRATISS } \\
\text { Fondo es çien braçadas: ique vos aventurades?- (149) < ADVENTURATISS }\end{array}$ & òoóo oóo o oóo / oó oòoóo \\
\hline E lo mejor del malo, que mal d'él non ayades, < HABEATISS & oòoó oóo / oóo òoóo \\
que ningún bien, fallarlo en él non entendades. (161) < INTENDATíS & òoó òoóo / oóo òoóo
\end{tabular}

Durante los años de composición de los Proverbios morales, Sem Tob sintió como vulgares las variantes originadas por la pérdida de la consonante intervocálica, todavía no asimiladas por el sociolecto de mayor prestigio, rasgo 
lingüístico compartido por el Libro de miseria de omne, compuesto entre 13121330 (Pla 2015d).

b) En posición de rima se observa regularidad articulatoria de los pares fonemáticos /ts/ - /dz/ y /s/ - /z/ en el margen posvocálico, rasgo caracterizador del sociolecto culto.

Las pocas alternancias gráficas entre $<\mathrm{z}>\mathrm{y}<$ ç> de los manuscritos habrían sido causadas no solo por la intervención de los copistas sino también por la tendencia de la lengua castellana desde el siglo XIII al ensordecimiento del fonema sibilante africado sonoro, (Malkiel 1971; 1981; Pensado 1993a; Marcet), rasgo compartido por otras lenguas peninsulares norteñas como el aragonés.

Desde mediados del siglo XIV el paradigma fónico del sociolecto de mayor prestigio estaba todavía formado por tres pares de fonemas sibilantes $/ \mathrm{s} /-$ /z/, /S/-/3/y /ts/-/dz/. En la oralidad se constata la paulatina generalización de la pérdida de sonoridad del par africado, iniciada desde la centuria precedente, y la consecuente fricatización del resultado sordo ([s]) (Pla 2014a). La coexistencia del proceso de ensordecimiento y fricatización habría desembocado en una articulación dentoalveolar fricativa sonora ([z]) que se mantuvo allí donde perduró la diferencia de sonoridad (Ariza 2012).

El fenómeno de çeçeo, con resultado sordo generalizado, provocó variabilidad gráfica entre $<c ̧>\mathrm{y}<\mathrm{s}>$, como así desvelan las grafías de los manuscritos, rasgo coincidente con el componente fónico subyacente en los versos de López de Ayala (Pla 2014b). En el caso de la obra de Sem Tob se documentan las siguientes vacilaciones gráficas:

El loco es su soçobra que anda muy pagado, (15a) < SUB SUPRA fizo çoçobra d'esto en este mesmo día: $(87 \mathrm{~b})<$ SUB SUPRA

El plazer de la siençia es complido plazer; (623a) < SCIENTĬA e yacen çafondadas $(37 \mathrm{c})<$ *SUFFUNDATAS

\subsubsection{Palatales}

a) Se observa regularidad articulatoria entre $/ \delta / y / z /$. Únicamente se constata en el manuscrito aljamiado $C$ la confusión gráfica entre <tygeras $>(515 \mathrm{a})$ y $<$ tiseras $>$ (516b), producida por la confusión en la oralidad entre ambos fonemas fricativos, como se observa de forma incipiente en las rimas del Libro de 
Alexandre (1884) y el Libro de Apolonio (483), así como posteriormente en los versos de López de Ayala.

b) Son abundantes las rimas que demuestran diferencia articulatoria de los pares fonemáticos palatales $/ \mathrm{K} / \mathrm{y} / \mathrm{j} /$. La variabilidad gráfica entre $<\mathrm{l}>\mathrm{y}<\mathrm{ll}>$ trasluce, en ocasiones, una posible pervivencia de la articulación geminada lateral latina (Pensado 1993b) que, para Alarcos supone "combinaciones de una consonante alveolar con un elemento semiconsonántico palatal; mejor dicho, en su sistema semítico, combinaciones de un nun o un lam sucunados y un yā vocalizado" $(1951,271)$.

La rima homoioteleuton imposibilita conocer con total exactitud la articulación de la consonante intervocálica; sin embargo, la elección de las voces en rima, en consonancia con las distribuciones léxicas de los textos poéticos de la escuela del mester, así como su representación gráfica en la totalidad de los manuscritos conservados (<-ll->), apoya la teoría de la existencia de una articulación cercana a la geminación en la lengua castellana tardomedieval (Pla en prensa). Espinosa, asimismo, mantiene como posibilidad la existencia de esta articulación en el proceso de asimilación de la vibrante implosiva con la lateral explosiva [r.l] $>[1.1]$.

Las lectiones $<$ querellas $>$, $<$ rebellas $>\mathrm{y}<$ denostalle $>$ encubren una articulación [ke.rél.las] / [ke.rél.jas], [re.ßél.las] / [re.ßél.jas] y [de.nos.tál.le] / [de. nos.tál.je] en rima con [Ka.márle], caso último que parece confirmar la existencia de la variante geminada, ya que por efectos de la rima homoioteleuton el segmento fónico [-le] es el único posible en posición de rima:

Fi d'omre, ¿que't t $^{9}$ querellas cuando lo que't plaze < QUERELLAS non se cumple, $e$ rrebellas en Dios porque non faze (298) < REBELLAS

Por end, non puedo cosa loar nin denostalle < DEHONESTARE ǏLLI nin dezirle fermosa, sol nin fea llamarle. (94) < CLAMARE ILLLI

c) De igual modo que en el Rimado de Palacio, permanecen variantes con palatal fricativa antihiática:

Pero por non yerrar ante es seso çierto $(187 \mathrm{a})<$ ERRARE Com el pez en el río viçioso e riyendo, $(409 \mathrm{a})<$ RIDĒNDU

9. Dada la métrica de los hemistiquios heptasílabos es conveniente mantener la apócope de los pronombres personales de segunda persona del singular. 


\subsubsection{Articulación de los grupos cultos}

La materialidad textual de los manuscritos conservados presenta abundantes casos de agrupaciones consonánticas, en contraste con la oralidad, en que se tendía a la simplificación de la consonante implosiva, por lo que en <escribto $>$ subyace una articulación simplificada ([es.krí.to]), en rima con <quito> $\mathrm{y}<$ fito $>:^{10}$
De peligro e mengua si quieres seer quito, $<$ QUITU
guárdate de tu lengua e más de tu escribto. (456) < SCRIPTU
E la razón que puesta non yaze en escrito < SCRIPTU
tal es como saeta que non llega al fito. (461) < FICTU

Hay casos que reflejan la pérdida de contenido fónico de la consonante explosiva, tras un proceso de asimilación articulatoria $\left([\mathrm{m} . \mathrm{b}]>{ }^{*}[\mathrm{~m} . \mathrm{m}]>[\mathrm{m}]\right)$. El manuscrito $C$ ofrece las variantes gráficas asimiladas, en tanto $M N E$ se caracterizan por el mantenimiento del grupo $<\mathrm{nb}\rangle$, contrariamente a los resultados esperados por parte del colectivo judeoespañol, lengua que conserva los grupos consonánticos sin asimilar (Ariza 1994). Del mismo modo que Sem Tob, otros textos poéticos medievales castellanos ofrecen asimilación regresiva de este grupo (como la estrofa 126 del Libro de Buen Amor):

Nunca de una camisa amas non se vistieron, (377a) < AMBAS

nin los camios que faze la rueda a menudo. (407b) < CAMBĪos

Su talente se camia de alegre a triste $(669 \mathrm{a})<$ CAMBĬA

\section{CONCLUSIONES}

El análisis de las rimas y la métrica de los versos de Sem Tob, en su contexto poético adecuado y a la luz de las herramientas proporcionadas por la Lingüística diacrónica, conduce a reafirmar que sus rasgos lingüísticos se co-

10. Tendencia fónica que habría afectado a la articulación de los nombres propios. En la estrofa 466, en que tiene lugar el desarrollo del tópico medieval del debate sobre armas y letras, la voz $<$ fito $>$ está en rima con <aibto $>($ ms. C) / <Egibto $>$ (ms. $M) /<$ Egipto $>$ (mss. $E$ y N). En todos los manuscritos se conserva el grupo culto que en la oralidad simplificó en una dental oclusiva sorda: Que la saeta lança fasta un çierto fito, < FICTU e la letra alcança de Burgos a Aibto; < AEGYPTUS 
rresponden con los de la lengua castellana durante el reinado de Alfonso XI (1312-1350) y principios del de Pedro I (1350-1369), a saber: la apertura del proceso de desfonologización de los fonemas bilabiales (todavía en estado latente), la pervivencia de una articulación geminada lateral, en convivencia con la solución palatalizada, los incipientes casos de çeçeo, la monoptongación del sufijo /-iello/ > /-illo/, la contienda de formas del paradigma verbal de pretérito imperfecto y condicional y el rechazo por las formas léxicas apocopadas.

La elección de este molde estrófico, como ya se ha apuntado anteriormente, comparte el mismo marco cultural que el de otros poetas que decidieron verter sus obras en la tradición poética castellana de mayor prestigio, es el caso de Juan Ruiz, el exbeneficiado de Úbeda o el autor anónimo del Libro de miseria de omne. La decisión de agrupar los versos en dísticos se debió, como ya han apuntado otros investigadores, a la influencia ejercida por la tradición discursiva didáctico-moral, de la que Sem Tob era gran conocedor. A su vez, la crítica a la codicia, eje vertebrador del Libro de miseria de omne, la paciencia del hombre sabio, que retomará López de Ayala, y la absoluta intimidad que transmiten los versos del rabí constituyen parámetros configurativos de los textos poéticos del segundo ciclo de la escuela del mester, que comparten la cosmovisión de un mundo en continuo cambio (López Castro).

Los rasgos articulatorios descritos, cultos, pero no arcaizantes, como la tendencia latente en la métrica de los versos a la estructura tautosilábica, en estrecha relación con el empleo de la sinalefa, confieren innovación al texto en lo concerniente a su materialidad lingüística. De esta manera, el resultado métrico-silábico del poema responde a un fenómeno lingüístico más amplio: la regularización de las variantes silábicas y la tendencia a la estructura abierta (CV) que tuvo lugar durante el reinado de Alfonso Onceno, pese al mantenimiento en la oralidad de formas residuales con pérdida vocálica, que sirvieron al poeta como herramienta para regularizar la métrica de sus versos alejandrinos. La convivencia de ciertas variantes, permitidas por la caracterización lingüística de la época, no parece casual en el juego verbal del que hace gala Sem Tob a lo largo de su poema, siempre en beneficio del isosilabismo pretendido.

Proverbios morales es un texto, por tanto, fruto del mestizaje cultural del que hace gala el intelectualismo del autor y compuesto, asimismo, según los criterios de la nueva estilística del segundo ciclo del mester de clerezía, en el contexto de una experiencia poética de emoción lírica y transformación métrica. 


\section{OBRAS CITADAS}

Alarcos Llorach, Emilio. "La lengua de los Proverbios morales de don Sem Tob”. Revista de Filología Española 35.1 (1951): 249-309.

Alarcos Llorach, Emilio. “Trece apostillas al texto de Sem Tob”. Dicenda: cuadernos de Filología Hispánica 6 (1987): 59-66.

Alarcos Llorach, Emilio. Fonología española. 1965․ Madrid: Gredos, 1990.

Alonso, Dámaso. "Temas y problemas de la fragmentación fonética peninsular”. 1962. Obras completas, I: Estudios lingüísticos peninsulares. Madrid: Gredos, 1972. 13-291.

Ancos, Pablo. Transmisión y recepción primarias de la poesía del mester de clerecía. Valencia: Publicacions de la Universitat de València, 2012.

Anónimo. Libro de miseria de omne. Ed. Jaime Cuesta Serrano. Madrid: Cátedra, 2012.

Ariza, Manuel. "El judeoespañol". Sobre fonética histórica del español. Madrid: Arco/libros, 1994. 203-21.

Ariza, Manuel. Fonología y fonética históricas del español. Madrid: Arco/libros, 2012.

Baer, Yitzhak. Historia de los judíos en la España cristiana. Ed. J. L. Lacave. Madrid: Altalena, 1981.

Barberia, Irene. "Vowel Quality Effects on Hiatus Resolution in Spanish". Papers in Linguistics by the BIDE Generation (Anuario del Seminario de Filología Vasca "fulio de Urquijo"). Eds. Rebeka Campos-Astorkiza y Jon Franco. 46.1 (2012): 73-82.

Castro, Américo. España en su historia: cristianos, moros y judíos. 1948. Barcelona: Crítica, 1983.

Catalán, Diego. "En torno a la estructura silábica del español de ayer y del español de mañana". 1971. El español: orígenes de su diversidad. Madrid: Paraninfo, 1989. 77-104.

Company, Concepción. "Condicionamientos textuales en la evolución de los adverbios en -mente". Revista de Filología Española 92.1 (2012): 9-42.

CORDE: Real Academia Española. Banco de datos [en línea]. Corpus diacrónico del español. <http://www.rae.es> [10 de diciembre de 2015].

Corominas, Juan, y José Antonio Pascual. Diccionario Crítico Etimológico Castellano e Hispánico. 1980-1991. 6 volúmenes. Madrid: Gredos, 2006-2007.

Deyermond, Alan D. Historia de la literatura española, I: La Edad Media. Barcelona: Ariel, 2003. 
Díaz-Mas, Paloma, y Carlos Mota, eds. "Introducción”. Sem Tob de Carrión. Proverbios morales. Madrid: Cátedra, 1998. 9-92.

Domínguez Caparrós, José. "La métrica de la copla sefardí". Rhythmica 3.4 (2006): 45-61.

Domínguez Caparrós, José. Métrica española. Madrid: UNED, 2014.

Echenique, María Teresa. "El sistema referencial en español antiguo: leísmo, laísmo y loísmo”. Revista de Filología Española 61 (1981): 113-57.

Echenique, María Teresa. "Fuentes y vías metodológicas para el estudio de la pronunciación castellana a través de su historia: de Amado Alonso al siglo XXI". Historia de la pronunciación de la lengua castellana. Eds. María Teresa Echenique y Francisco Javier Satorre. Valencia/Neuchâtel: Tirant lo Blanch, 2013. 29-60.

Echenique, María Teresa. "Los pronombres átonos de tercera persona en castellano medieval: punto de partida y antecedentes de su formación futura". Morfología histórica del español en América (MORPHISPAM). Volumen 1. Eds. Juan P. Sánchez Méndez y Elena Rojas Maier. En prensa.

Espinosa Elorza, Rosa María. "Lo que la ll esconde". La historia del español hoy: estudios y perspectivas. Eds. José Luis Ramírez Luengo y Eva Patricia Velásquez Upegui. Lugo: Axac, 2014. 11-25.

Folgar, Carlos. "Apócope, restitución vocálica, estructura de la sílaba: observaciones sobre los pronombres clíticos apocopados". Cum corde et in nova grammatica: estudios ofrecidos a Guillermo Rojo. Eds. Tomás E. Jiménez Juliá, Belén López Meirama, Victoria Vázquez Rozas y Alexandre Veiga Rodríguez. Santiago de Compostela: Universidade de Santiago de Compostela, 2012. 329-39.

Folgar, Carlos. "Nuevas aclaraciones sobre la apócope extrema medieval a la luz de la "jerarquía de la apócope". La historia del español hoy: estudios y perspectivas. Eds. José Luis Ramírez Luengo y Eva Patricia Velásquez Upegui. Lugo: Axac, 2014. 27-32.

Freixas, Margarita. "La apócope en el Libro de Buen Amor". Moenia 7 (2001): 393-418.

García Velasco, Marcelino. "El Rabí Don Sem Tob, judío de Carrión, visto por un poeta a través de su obra Glosas de sabiduría o Proverbios morales". Publicaciones de la Institución Tello Téllez de Meneses 73 (2002): 225-43.

Girón Negrón, Luis Manuel. "La clerecía rabínica: siglos XIV-XV". Historia de la métrica medieval castellana. Coord. Fernando Gómez Redondo. La Rioja: Cilengua, 2016. 275-301. 
González Llubera, Ignacio. “The Text and Language of Santob de Carrión's Proverbios morales”. Hispanic Review 8.2 (1940): 113-24.

González Llubera, Ignacio. "A Transcription of Ms. $C$ of Santob de Carrión's Proverbios morales". Romance Philology 4.1 (1950): 217-56.

Hilty, Gerold. "La figura del juglar en la Castilla del siglo XIII". Versants 28 (1995): 153-73.

Ivanovici, Víctor. "Sem Tob de Carrión: un poeta «sefardí» en la España medieval”. CECYM: Centro de Estudios Clásicos y Medievales. Cátedra 1 (2003): $1-23$.

Kleinschmidt, Harald. Comprender la Edad Media: la transformación de ideas y actitudes en el mundo medieval. Madrid: Akal, 2009.

Lapesa, Rafael. Historia de la lengua española. 9. ${ }^{a}$ ed. Madrid: Gredos, 1981.

Lapesa, Rafael. "La apócope de la vocal en castellano antiguo: intento de explicación histórica". 1951. Estudios de historia lingüística española. Madrid: Paraninfo, 1985a. 167-97.

Lapesa, Rafael. "Contienda de normas lingüísticas en el castellano alfonsí". 1982. Estudios de historia lingiuística española. Madrid: Paraninfo, 1985b. 209-25.

Lapesa, Rafael. "Sobre los orígenes y evolución del leísmo, laísmo y loísmo". 1968. Estudios de morfosintaxis histórica del español. Eds. Rafael Cano y María Teresa Echenique. Madrid: Gredos, 2000a. 279-310.

Lapesa, Rafael. "Las formas verbales de segunda persona y los orígenes del voseo”. 1970. Estudios de morfosintaxis histórica del español. Eds. Rafael Cano y María Teresa Echenique. Madrid: Gredos, 2000b. 682-97.

Lapesa, Rafael. "Morfosintaxis histórica del verbo español". Estudios de morfosintaxis histórica del español. Eds. Rafael Cano y María Teresa Echenique. Madrid: Gredos, 2000c. 730-887.

Lázaro Carreter, Fernando, "La poética del arte mayor castellano". Studia Hispanica in Honorem R. Lapesa. Madrid: Gredos, 1972. 343-78.

López Bobo, M. ${ }^{a}$ José. "Laísmo y loísmo en el Libro de Buen Amor". Epos 7 (1991): 593-607.

López Castro, Armando. "Pensamiento y lenguaje en los Proverbios Morales de Sem Tob". Medioevo y Literatura (Actas del V Congreso de la Asociación Hispánica de Literatura Medieval). Ed. Juan Paredes. Granada: Universidad de Granada, 1995. 61-69.

López de Ayala, Pero. Rimado de Palacio: esbozo de edición crítica por Rafael Lapesa Melgar con la colaboración de Pilar Lago [con un estudio introductorio 
de Giuseppe Di Stefano]. Valencia: Generalitat Valenciana/Consellería de Cultura i Esport/Biblioteca Valenciana, 2010.

Malkiel, Yakov. "Towards a Reconsideration of the Old Spanish Imperfect in -ía -ie”. Hispanic Review 27 (1959): 435-81.

Malkiel, Yakov. "Derivational Transparency as an Occasional Co-Determinant of Sound Change: A New Causal Ingredient in the Distribution of $-c ̧$ - and $-z$ - in Ancient Hispano-Romance (I)". Romance Philology 25 (1971): 1-52.

Malkiel, Yakov. "A Hidden Morphological Factor behind Instances of Erratic Distribution of $c$ and $z$ in Old Spanish". Romance Philology 35 (1981): $105-29$.

Manzano, Eduardo. Épocas medievales. Barcelona: Crítica, 2010.

Marcet, Vicente. "Contribución al estudio del ensordecimiento de las sibilantes en el castellano norteño: los documentos de Miranda de Ebro (siglo XIV)". Actas del IX Congreso Internacional de Historia de la Lengua Española (Cádiz, 2012). Coords. Teresa Bastardín Candón y Manuel Rivas Zancarrón. Madrid: Iberoamericana Vervuert, 2015. 507-22.

Matute Martínez, Cristina. Los sistemas pronominales en español antiguo: problemas y métodos para una reconstrucción bistórica. Madrid: ed. de la autora/ Universidad Autónoma de Madrid, 2004. Diciembre de 2015. <http:// www.lllf.uam.es/coser/publicaciones/cristina/1_es.pdf>.

Mota Placencia, Carlos. "Algo más sobre la versificación de los Proverbios morales de Sem Tob de Carrión”. Actas del VIII Congreso Internacional de la Asociación Hispánica de Literatura Medieval. Eds. Margarita Freixas y Silvia Iriso. Santander: Consejería de Cultura del Gobierno de Cantabria, 2000. 1369-82.

Navarro, Tomás. Manual de pronunciación española. 2. ${ }^{a}$ ed. Madrid: CSIC, 1972.

Nieuwenhuijsen, Dorien. "Cambios en la colocación de los pronombres átonos". Sintaxis histórica de la lengua española. Dir. Concepción Company Company. Volumen 1. Tomo 2. México: Fondo de Cultura Económica/ UNAM, 2006. 1339-404.

Pensado, Carmen. "El ensordecimiento castellano: ¿un fenómeno extraordinario?”. Anuario de linguiistica bispánica 9 (1993a): 197-231.

Pensado, Carmen. "Consonantes geminadas en la evolución histórica del español”. Actas del Primer Congreso Anglo-Hispánico, I: Lingüística. Ed. Ralph Penny. Madrid: Castalia, 1993b. 193-204. 
Perry, Theodore A. The Moral Proverbs of Santob de Carrion: Fewish wisdom in Christian Spain. Princeton: Princeton UP, 1987.

Pla Colomer, Francisco P. Métrica, rima y oralidad en el Libro de Buen Amor. Anejos de Quaderns de Filologia 80. Valencia: Universitat de València, 2012.

Pla Colomer, Francisco P. Letra y voz de los poetas en la Edad Media castellana. Valencia/Neuchâtel: Tirant Humanidades, 2014a.

Pla Colomer, Francisco P. "Letra y voz de Ayala: canciller entre tradición y vanguardia”. Revista de Historia de la Lengua Española 8 (2014b): 113-48.

Pla Colomer, Francisco P. "Componiendo una façion rimada: caracterización métrico-fonética de la Vida de San Ildefonso". Literatura y ficción: "estorias", aventuras y poesía en la Edad Media. Vol. 1. Ed. Marta Haro Cortés. Valencia: Publicacions de la Universitat de València, 2015a. 303-18.

Pla Colomer, Francisco P. "De nuevo sobre letra y voz del Arcipreste: en defensa de la edición de J. Corominas". Revista de Historia de la Lengua Española 9 (2015b): 175-88.

Pla Colomer, Francisco P. "Métrica y pronunciación en el Libro de Buen Amor: prototipo del isosilabismo castellano medieval”. Analecta Malacitana 38.1-2 (2015c): 55-78.

Pla Colomer, Francisco P. "Mester es que las palabras sepa bien silabificar: estudio filológico del Libro de miseria de omne". Rivista di Filologia e Letterature Ispaniche 18 (2015d): 9-42.

$\mathrm{Pla}$ Colomer, Francisco P. "Articulación geminada lareral en castellano medieval: el testimonio de los textos poéticos”. Revista de Filología Española. En prensa.

Recasens, Daniel. Coarticulation and Sound Change in Romance. Amsterdam: John Benjamins, 2014.

Ruiz, Juan. Libro de Buen Amor. Ed. Joan Corominas. Madrid: Gredos, 1967.

Santob de Carrión. Proverbios Morales. Ed. Ignacio González Llubera. Cambridge: University of Cambridge, 1947.

Sem Tob de Carrión. Proverbios morales. Ed. Guzmán Álvarez. Salamanca: Anaya, 1970.

Sem Tob de Carrión. Proverbios morales. Ed. Sanford Shepard. Madrid: Castalia, 1985.

Sem Tob de Carrión. Proverbios morales. Eds. Paloma Díaz-Mas y Carlos Mota. Madrid: Cátedra, 1998. 
Sem Tob de Carrión. Sermón de glosas de sabios y otras Rimas. Ed. Agustín García. Zamora: Lucina, 2000.

Shepard, Sanford. Shem Tov: His world and his words. Miami: Ediciones Universal, 1978.

Taylor, Barry. "Sem Tob de Carrión, Proverbios morales". Diccionario filológico de literatura medieval española: textos y transmisión. Eds. Carlos Alvar y José Manuel Lucía Megías. Madrid: Castalia, 2002. 941-45.

Uría Maqua, Isabel. "Los Proverbios morales de Sem Tob de Carrión y su relación con el mester de clerecía". Las tres culturas en la corona de Castilla y los sefardíes. Valladolid: Consejería de Cultura y Bienestar Social, 1990. $31-47$.

Uría Maqua, Isabel. Panorama crítico del mester de clerecía. Madrid: Castalia, 2000.

Walsh, John K. "La Vida de San Alifonso por metros (ca. 1302)". Romance Philology. Supplement to vol. 46.1 (1992).

Wartburg, Walther v. Französisches Etymologisches Wörterbuch. Tübingen: J. C. B. Mohr (Paul Siebeck), 1949.

Zemke, John M. Critical Approaches to the Proverbios morales of Shem Tov de Carrión: An Annotated Bibliography. Newark: Juan de la Cuesta, 1997. 